\section{Trabajadores intelectuales e industrias culturales}

\author{
Daniel E. Jones
}

Este artículo analiza la relación exis-

E tente entre los diferentes tipos de "trabajadores intelectuales" y las "industrias culturales y comunicativas" desde una perspectiva crítica. Este amplio colectivo -dentro del cual los intelectuales "puros" serían solo una pequeña parte, aunque muy relevante-, se caracteriza por estar constituido por un conjunto de personas cuyo estatus social y laboral le viene dado, en buena medida, por su mayor o menor relación de dependencia económica con las empresas que conforman las industrias culturales y comunicativas, productoras y comercializadoras de cultura y comunicación de élite y de masas, preferentemente privadas, tanto nacionales como transnacionales. El artículo estudia la interrelación de los trabajadores intelectuales con estas empresas culturales y comunicativas y no las posturas de aquellos frente a estas, fenómeno este último que ha dado lugar a una abundante y contradictoria bibliografía entre los que han sido llamados "apocalípticos" y los "integrados".

\section{Introducción}

Desde hace ya unos cuantos años se pretende desentrañar la intrínseca relación existente entre los "trabajadores intelectuales" y las "industrias culturales y comunicativas" -conceptos de difícil definición-, pero el resultado no parece del todo satisfactorio. Los diferentes autores que han intentado pre- 
cisar las características y los contornos de ambos sectores llegan a conclusiones dispares y a veces hasta contrapuestas.

En estas páginas se intenta analizar esta relación, referida particularmente a la situación actual, y el punto de partida radica en la utilización de estos conceptos en sentido amplio y desde una perspectiva crítica. Es decir, se utilizará en general la definición de "trabajadores intelectuales" -entre los que los intelectuales "puros" serían solo una pequeña parte, aunque muy relevante- para referirse al conjunto de personas cuyo estatus social y laboral le viene dado, en buena medida, por su mayor o menor relación de dependencia económica con las empresas que conforman las industrias culturales y comunicativas, que, dentro de su variedad y complejidad, producen y comercializan tanto cultura de élite como cultura de masas, y son preferentemente privadas.

Los conceptos de "industria cultural", "industria de la información", "industria de la comunicación", "industria del entretenimiento" y otras similares como "industria de contenidos", "industria del conocimiento", "industria del ocio" o "industria del espectáculo", no dejan de ser bastante imprecisos, ambiguos y parciales, ya que sobre to- do dependen del punto de vista que se adopte en el análisis. En efecto, aunque se trata de industrias en las cuales intervienen diferentes clases de actores empresariales (públicos/privados; nacionales/transnacionales), que realizan diversos tipos de actividades (desde la concepción de la idea hasta su venta o cesión al destinatario o consumidor final) y utilizan variados tipos de soportes (tradicionales o digitales), están intrínsecamente relacionadas entre sí. ${ }^{1}$

Por ello, los diferentes autores interesados en estos estudios desde las perspectivas económica y sociológica (la Escuela de Francfort o los funcionalistas norteamericanos de la Mass Communications Research en los años cuarenta) no se han acabado de poner de acuerdo en la delimitación del campo de estudio ni en los diferentes elementos y segmentos que componen estas industrias, que fabrican en serie pero que tienen también una gran parte de actividad artesanal o de producción de prototipos.

Algunos autores han puesto el acento solo en los grandes medios de comunicación de masas (el sistema comunicativo o mediático), es decir la prensa, la radio y la televisión, y en algunos casos también la publicidad. Otros han añadido algunas industrias culturales importantes, como la cine-

1 JONES, Daniel E. "Democràcia, comunicació i negoci: el creixement desmesurat de la concentració econòmica”. Trípodos 10. Barcelona: URL, 2001. 
matográfica, y unos pocos más la editorial, la fonográfica y la videográfica.

No obstante, hay otros que han considerado como "industrias culturales" también el teatro, la música, la danza, las artes plásticas y del espectáculo o el patrimonio histórico, que han sumado a las otras más tradicionales y en algunos casos deficitarias (cine, libro, disco), aunque consideramos que son de otro ámbito. ${ }^{2}$

El artículo se preocupa, entonces, del análisis de la interrelación de los trabajadores intelectuales con las industrias culturales y comunicativas y no las posturas de aquellos frente a estas, fenómeno este último que ha dado lugar a una abundante y contradictoria bibliografía entre los que han sido llamados "apocalípticos" y los "integrados". 3

Entre los autores que se considera más interesantes para sustentar esta argumentación se encuentran quienes intentan definir las industrias culturales y comunicativas -Bozal, 1972; Williams, 1982; Mattelart-Piemme, 1982; Giraud, 1982; Garnham, 1985; Towse, 2005- y quienes intentan encontrar una tipología pertinente del conjunto de intelectuales o de sus componentes más significativos: Gramsci, 1967; Bozal, 1972; Romano, 1977; Rositi, 1980; Konrád-Szelenyi, 1981; Williams, 1982;
Berrio-Saperas, 1993; Juliá, 2005; Ovejero Lucas, 2004.

\section{Para una definición del "trabajador intelectual"}

Los diversos autores cuya obra se ha consultado para la elaboración de este artículo se refieren a sujetos diferentes al definir a los "intelectuales", por lo que conviene primeramente hacer un breve repaso a estas definiciones.

Antonio Gramsci (1967) sostiene la conocida tesis de que todos los seres humanos son intelectuales, aunque no todos ellos tienen esta función preferente en la sociedad. A partir de esta primera afirmación, distingue entre intelectuales de tipo tradicional (literatos, filósofos y artistas) y los de nuevo tipo (científicos y técnicos); los de tipo rural (sacerdotes, abogados, maestros, notarios, médicos) y los de tipo urbano (tecnócratas de la industria); finalmente, los de tipo tradicional (pretendidamente al margen de los grupos sociales fundamentales) y los orgánicos (al servicio de un partido de clase).

Al propio tiempo, sostiene que se han de contemplar diversos grados en el colectivo intelectual, de la misma manera como ocurre en el ejército: mientras que en el escalafón más alto se debe situar a los pensadores y cre-

2 Ibídem.

3 ECO, Umberto. Apocalípticos e integrados ante la cultura de masas. Barcelona: Lumen, 1968. 
adores de las diversas ciencias, de la filosofía y del arte, en los grados subalternos cabe colocar a los más humildes "administradores" y divulgadores de la riqueza intelectual acumulada con la tradición. ${ }^{4}$

Otro autor marxista, Raymond Williams (1982), afirma que la propia definición de "intelectual" es problemática y contradictoria, pues un análisis en profundidad revela que constituye, en primer término, una especialización falsa a partir de un colectivo más general de trabajadores culturales $y$, en segundo término, una extensión equivocada de un tipo de formación cultural a una categoría social general. Y esto es así, pues la categoría de "intelectuales", referida a cierto tipo de escritores, filósofos y pensadores sociales, que mantiene relaciones con un orden social y sus clases principales, es de hecho un colectivo específico, que no puede tomarse como representativo del conjunto de trabajadores culturales.

Williams se queja de que esta concepción aristocratizante del intelectual excluye, por una parte, a la gran variedad de artistas, intérpretes y trabajadores culturales que no pueden ser definidos como "intelectuales" en sentido estricto, pero que colaboran con sus obras ampliamente a la cultura gene- ral. Excluye, por otra parte, a los variados tipos de trabajadores intelectuales que están instalados en las instituciones políticas, económicas, sociales y religiosas fundamentales -funcionarios, expertos, sacerdotes, profesionales liberales- y que están claramente implicados, por este hecho, no solo en sus prácticas directas, sino también en la producción y reproducción social. ${ }^{5}$

En los antiguos países comunistas de la Europa del Este se acuñó la definición de George Konrád e Ivan Szelenyi, quienes -no obstante dedicar su análisis a los intelectuales bajo el "socialismo de Estado"- señalaban algunas características comunes de estos con los de la sociedad capitalista occidental y tendían a considerar como "intelectuales" a todos los profesionales cualificados. Sostenían que en el capitalismo occidental moderno los intelectuales transforman en mercancía las ideologías que elaboran y se ofrecen ellos mismos en alquiler a las verdaderas clases sociales cuyas ideologías se dedican a formular, y de las que son su inspiración, en suma, su inteligencia. Esta situación figura en abierta contradicción con la misión moral primitiva del sacerdocio; de ahî que el término "profesional" resulte una descripción más precisa de la situación social de los intelectuales. ${ }^{6}$

4 GRAMSCI, Antonio. Cultura y literatura. Madrid: Ediciones Península, 1967.

5 WILLIAMS, Raymond. Cultura: Sociología de la comunicación y del arte. Barcelona: Paidós, 1982.

6 KONRÁD, George e Ivan SZELENYI. Los intelectuales y el poder: "Intelligentsia" y poder de clase en los países socialistas europeos. Barcelona: Ediciones Península, 1981. 
Mientras que las sociedades comunistas consideraban a los intelectuales como expertos que trabajaban en especialidades definidas, los países capitalistas les obligan a elegir entre profesiones, generalmente con rango universitario. Este estatus profesional les permite a los intelectuales occidentales mantener una posición estructural intermedia que los coloca en parte en la situación de propietarios del capital, parte en la de propietarios de mano de obra, lo cual les ayuda a decidir autónomamente al llegar a ser el estrato intelectual orgánico de una u otra clase. Es decir que los intelectuales, como productores de conocimiento especializado, no poseen capital ni bienes de producción, por lo que se parecen mucho más a los trabajadores manuales. Pero el carácter especial del conocimiento intelectual los aleja de estos. La intelligentsia se ubica más cerca del "proletariado" con respecto a su relación laboral, pero más cerca de la "burguesía" en función de sus ingresos y estilo de vida.7

Algunos intelectuales aparecen en el mercado, sin embargo, no solo como poseedores de mano de obra, sino también en cierto sentido como propietarios de capital. Pueden emplear, asimismo, sus aptitudes especializadas como un medio de producción y, por tanto, muchos de ellos no ofrecen tanto su mano de obra como los productos intelectuales de su conocimiento: una obra literaria, una sinfonía o una escultura. Por tanto, un considerable porcentaje de intelectuales goza de la oportunidad de ser casi un empresario mejor que un trabajador asalariado cuya mano de obra, vendida en el mercado, va destinada a producir beneficios a los empresarios de la cultura y la comunicación.

En el capitalismo actual, por tanto, el colectivo intelectual, más que ocupar una posición intermedia entre empresarios y trabajadores, tiende a dividirse en tres niveles bastante definidos. De una parte, un grupo de intelectuales con bastante influencia, que llega a compartir en muchos aspectos el poder económico con los propietarios del capital y el poder político con los representantes democráticos. Sin embargo, al mismo tiempo, otros grupos de intelectuales son directamente "proletarizados", y llegan a ser simples poseedores de mano de obra. Aparece, asimismo, un nivel intermedio que actúa como colchón entre los dos extremos. ${ }^{8}$

Esta tesis enlaza con la de Gramsci, expuesta anteriormente -quien comparaba el conjunto de intelectuales con instituciones de estructura piramidal como el Ejército, con diferentes poderes y

7 Ibídem.

8 Ibídem. 
atribuciones-, y con la de Franco Rositi, quien sostiene que de la sociedad civil y del mercado libre de la opinión pública en donde se forman, los intelectuales pueden ser reclutados para desempeñar funciones de dirección en el ámbito económico, político y social. Es más, el poder y el conocimiento tienen que avanzar juntos, ya que el primero legitima al segundo. Pero de esta forma se crea un excedente de intelectuales con respecto a la cantidad de funciones directivas necesarias, es decir, que aparece un espacio cada vez mayor para aquel tipo de intelectual "socialmente desarraigado" o sin funciones precisas en el organigrama del poder.?

Por ello no conviene sobrevalorar el papel político de los intelectuales, quienes constituyen únicamente uno de los resultados de las relaciones de clase anteriores a su existencia. Están muy estratificados y por tanto son difícilmente agregables políticamente, ya que entre el intelectual en paro y el intelectual encumbrado en el poder existe una amplia gama de diferentes posiciones. En cualquier caso, son un grupo pequeño, al menos cuando no son asimilados, de forma abusiva, a todos los trabajadores no manuales. Poseen tradiciones ideológicas individuales, son mantenidos en la práctica en zo- nas de trabajo separadas de la clase productiva de la sociedad y, en general, son también improductivos, es decir consumidores de un excedente producido por otros. ${ }^{10}$

En resumen, se puede afirmar que si bien no existe una clara coincidencia en la definición de lo que es un intelectual desde una perspectiva crítica, y cuál es su papel político e ideológico entre las clases sociales fundamentales, queda suficientemente explícito que hay distintos tipos de intelectuales según su formación específica -humanistas o cientificos, por ejemplo- y según su papel y situación laboral y política dentro de la pirámide social: autónomos o asalariados, y de alto, medio o bajo rango.

Lo que se pretende en este artículo, en suma, es intentar establecer una tipología de los intelectuales o, más genéricamente, de los trabajadores intelectuales. Para ello se considera de sumo interés analizar las relaciones materiales que se establecen entre estos profesionales y las empresas de las industrias culturales y comunicativas para las que trabajan -públicas o privadas, nacionales o transnacionales, de cultura de élite o de cultura de masas- o bien que les sirven como canales vehiculizadores para sus mensajes. Pues, como sostiene Toffler, ${ }^{11}$ estas industrias cons-

9 ROSITI, Franco. Historia y teoría de la cultura de masas. Barcelona: Gustavo Gili, 1980.

10 Ibídem.

11 TOFFLER, Alvin. Los consumidores de cultura. Buenos Aires: Ediciones Siglo Veinte, 1967. 
tituyen una maquinaria física y social, comercial y de influencia, dedicadas primordialmente a dar forma material y distribuir los bienes y servicios producidos por los artistas y pensadores.

\section{Tipología de los trabajadores intelectuales}

Se pasará ahora a perfilar una posible tipología de los trabajadores intelectuales, que viene determinada, precisamente, por la estrecha relación material existente entre estos profesionales y las empresas de las industrias culturales y comunicativas. Para ello se utilizará, al igual que para explicar la estructura básica de este tipo de industrias, una metáfora espacial.

El modelo que se intenta describir aquí es concebido en forma piramidal -como el conjunto del sistema social-, con grandes contradicciones internas y con elementos más o menos estables. No se trata en ningún caso de un sistema cerrado, pues las interrelaciones con el sistema político y económico nacional y con el sistema cultural y comunicativo transnacional son decisivas. Además, existe un cierto paralelismo entre el estatus social -de prestigioalcanzado por los diferentes actores que conforman el colectivo de trabajadores intelectuales y el estatus económico -de relación laboral- con respecto a las diferentes empresas de la cultura y la comunicación, tanto públicas como privadas, y con los distintos niveles de la administración.
Esta pirámide podría ser dividida en dos mitades de arriba abajo y una de ellas la constituirían los intelectuales bumanistas y la otra los intelectuales científicos. Esta división resulta, sin embargo, cada vez más arbitraria debido sobre todo a que las dos culturas están consiguiendo un grado de integración sorprendente y bien puede hablarse ya de que el humanista es un intelectual especializado -un "científico"- a su manera, debido, a su vez, a una creciente parcelación del conocimiento humanístico (Rositi, 1980; Cueto, 1982; BerrioSaperas, 1993; Ovejero Lucas, 2004; Juliá, 2005). La mitad correspondiente a los humanistas podría dividirse, a su vez, en tres partes, siguiendo el modelo de las bellas artes clásicas, en letras, artes plásticas y música-teatro, pues los profesionales culturales suelen actuar preferentemente en uno de estos tres ámbitos, aunque en medios audiovisuales como el cine o la televisión se tienda cada vez más a una integración de estas especialidades.

En el plano vertical se podrían establecer los tres niveles jerárquicos siguientes:

- En la cúspide estarían los profesionales intelectuales (autónomos) de alto rango, de importante cotización en el mercado y reconocimiento de sus pares, que trabajan generalmente como profesionales liberales; se trata de los grandes escritores, filósofos, ensayistas y lite- 
ratos (es decir, los intelectuales "puros"); los grandes artistas plásticos; los grandes músicos y hombres de teatro (autores e intérpretes), y los grandes científicos de las distintas ramas del saber.

- En el centro estarían los profesionales intelectuales (autónomos o asalariados) de rango medio, que trabajan como profesionales liberales o como asesores o directivos del propio aparato cultural público o privado; se trata de los escritores en general, críticos literarios, periodistas, profesores de universidad y traductores especialistas de grandes obras extranjeras; los artistas plásticos, cineastas, críticos y profesores de arte; los músicos, actores, críticos y profesores de música preferentemente clásica, y los cientificos.

- En la base estarían los trabajadores intelectuales (asalariados) de bajo rango, es decir, los escritores de literatura de masas, guionistas de cine, radio y televisión, periodistas, publicitarios y traductores; los artistas plásticos de géneros masivos (cineastas, videoastas, cartelistas, diseñadores, grafistas, dibujantes o fotógrafos); los músicos y actores de reparto, y los divulgadores científicos.

Estos tres estratos verticales, como las distintas especialidades horizonta- les, no constituyen en modo alguno compartimentos estancos sino que existe una cierta movilidad entre sus miembros. Se produce, por tanto, una pugna constante entre los intelectuales que ya han alcanzado su meta y pretenden, por esto mismo, que se restrinja el número de competidores cualificados para el estatus de "intelectual", y los jóvenes que luchan por ascender por los cauces relativamente estrechos de la movilidad social. ${ }^{12}$

Por otra parte, se producen grandes diferencias de estatus según especialidades de mayor o menor solera y tradición. Por ejemplo, ante dos intelectuales de igual o parecida valía, uno proveniente de la literatura y otro del cine, tendrá aquel siempre más prestigio social o académico que este, fenómeno que coadyuva a su inclusión en uno u otro nivel jerárquico. Sin embargo, es muy probable que ambos se relacionen con las industrias culturales y comunicativas como profesionales liberales o como asalariados, según su estatus.

En estrecha relación con la pirámide se encuentran los diferentes "públicos" - desde una perspectiva sociopolítica- o los diferentes "consumidores" de cultura -desde una perspectiva económica-, aunque todos los miembros de la pirámide son a la vez, pero en distintas circunstancias, emisores o receptores comunicativos, característica

12 KONRÁD, George e Iván SZELENYI. Op. cit. 
que no comparten los públicos consumidores debido a la unidireccionalidad de los mensajes masivos en nuestra sociedad.

En cuanto a la relación con las empresas de las industrias culturales y comunicativas, se advierte que cuanto más arriba de la pirámide se encuentran, la dependencia laboral de aquellas es menor y, cuanto más abajo, mayor. Es decir, que mientras los profesionales intelectuales de alto rango se encuentran un tanto por encima de estos sectores industriales -su actitud suele ser de tipo "apocalíptico" frente a la cultura de masas-, los profesionales intelectuales de tipo medio son grandes beneficiarios de las industrias culturales y comunicativas -pues suelen obtener grandes éxitos de ventas de sus obras u ocupan cargos directivos; están por tanto más "integrados"y los trabajadores intelectuales proletarizados son en su inmensa mayoría asalariados, subcontratados o subempleados como sus colegas de cualquier sector de la economía.

Como contrapartida, los profesionales intelectuales de alto rango tienen una mayor dependencia del aparato estatal y de las instituciones públicas, a través de las academias y universidades, los grandes premios y homenajes, las grandes exposiciones y la entrada en los museos, los grandes teatros dramáticos o líricos y los grandes centros de investigación. El "clientelismo" político, sin embargo, que ha sido denunciado insistentemente en los últimos años -detectable en todos los niveles de la administración y practicado por todos los partidos- afecta preferentemente a los profesionales intelectuales de rango medio. ${ }^{13}$

\section{Dependencia económica del trabajador intelectual}

Se pasará ahora a analizar brevemente la relación de cada uno de estos tres estratos de profesionales culturales con las empresas más importantes de estos sectores -tanto públicas como privadas- en cada una de las cuatro especialidades en que se ha dividido aquí su campo de acción, es decir, letras, artes plásticas, música-teatro y ciencias. Se espera no pecar, sin embargo, de una visión excesivamente humanística y decimonónica. En todo caso, parece no resultar del todo arbitraria esta clasificación si lo que se propone aquí es un análisis de estos profesionales desde el punto de vista de su relación con las industrias culturales y comunicativas y con la administración pública.

13 FAJARDO, José Manuel. "Los intelectuales y la resistible atracción del poder". Cambio 16 780. Madrid, 10 de noviembre de 1986. 


\section{Profesionales intelectuales (autónomos) de algo rango}

El estrato de profesionales intelectuales (autónomos) de alto rango estaría constituido por los que suelen considerarse a sí mismos y, a su vez, ser considerados por sus pares, como intelectuales en sentido estricto, sobre todo los escritores y pensadores, y cuyo paradigma en España sería José Ortega y Gasset. Por lo menos así los definen autores como Ayala (1979) o Miguel (1980), aunque de ninguna manera Bozal (1972), Rositi (1980) o Cueto (1982), quienes no quieren excluir de este grupo selecto a los científicos de las diferentes ramas del saber, entre los que los humanistas y literatos serían solo una parte.

De todas maneras, lo que sí se percibe con nitidez es que existe una mayor interdependencia con las industrias de la cultura y la comunicación por parte de los llamados "humanistas" (los intelectuales "puros") que por parte de los llamados "científicos", y su relación con aquellas viene dada, precisamente, por su especialidad. En cualquier caso, unos y otros actúan generalmente como profesionales liberales respecto del aparato cultural y comunicativo.
En líneas generales puede decirse que, en el caso de la industria editorial suelen conseguir la publicación de sus obras en ediciones muy cuidadas y con una difusión más o menos limita$\mathrm{da}$, salvo que obtengan una notoriedad masiva proveniente de los medios de comunicación; también suelen tener bastantes libros críticos en ediciones de lujo sobre su propia obra, con las necesarias reproducciones en el caso de los artistas plásticos. Su relación con la industria periodística suele ser indirecta a través de los críticos literarios, artísticos y musicales y de los divulgadores científicos; suelen firmar esporádicamente -sobre todo los literatos- artículos de opinión en espacios privilegiados de los grandes diarios de "referencia dominante" -El País, El Mundo, ABC o La Vanguardia en el caso español-; suelen firmar manifiestos conjuntos con otros profesionales de su condición sobre grandes temas políticos, éticos y sociales, y suelen colaborar asiduamente en las grandes revistas literarias y cientificas nacionales y extranjeras. ${ }^{14}$

Su relación con la radio y la televisión es muy esporádica, a través de programas de entrevistas o reportajes sobre su obra; también, a través de la adaptación esporádica de sus obras literarias, la programación de sus obras

14 JULIÁ, Santos. "Intelectuales en periódicos: de la estrella polar al observatorio crítico". El País. Madrid, 11 de mayo del 2005, p. 35. 
musicales o teatrales en espacios de carácter más o menos restringido o su interpretación de grandes obras clásicas (líricas o dramáticas), en el caso de divos. Su relación con la industria cinematográfica suele ser mínima, fundamentalmente a través de la adaptación de sus obras literarias o musicales. Finalmente, su relación con la industria fonográfica es prácticamente nula, salvo en el caso de los grandes autores e intérpretes musicales, para quienes es un canal imprescindible para la difusión de su obra.

En cuanto a su relación con el Estado y con las grandes instituciones públicas, ya se ha adelantado más arriba que es muy importante debido a la mutua conveniencia. Estos intelectuales consiguen doctorados bonoris cau$s a$ en universidades prestigiosas -nacionales o extranjeras-, entran en las academias y en los grandes institutos de investigación, consiguen grandes premios (Nacional, Cervantes, Príncipe de Asturias o Premi d'Honor de les Lletres Catalanes y tienen aspiraciones al Nobel), son miembros a su vez de jurados de premios importantes, reciben condecoraciones, homenajes, cargos públicos solo honoríficos, entran en los grandes museos públicos, teatros dramáticos y líricos, se les organizan grandes exposiciones antológicas sobre su obra y obtienen un gran reconocimiento internacional que les permite actuar como invitados en centros de prestigio extranjeros.

\section{Profesionales intelectuales (autónomos o asalariados) de rango medio}

El tipo de profesionales intelectuales (autónomos o asalariados) de rango medio está mucho más integrado en el sistema de las industrias culturales y comunicativas privadas, pero su relación con las grandes instituciones públicas es menor que en el caso anterior, salvo entre los que colaboran, por ejemplo, con la radio y la televisión pública, son asesores ministeriales o profesores universitarios. Como los de alto rango, suelen ser también profesionales liberales y, en algunos casos, están asimilados a instituciones culturales públicas o privadas en cargos de responsabilidad.

En cuanto a la industria editorial, se observa por una parte que en el campo de las letras se trata de escritores y periodistas famosos con una gran producción libresca de importantes tiradas, que consiguen los grandes premios de la iniciativa privada (Planeta, Nadal, Plaza \& Janés o Santillana, por ejemplo), al tiempo que hay otros que son traductores especialistas y editores críticos de obras ajenas o directores de colecciones literarias y de ciencias sociales o naturales. Por su parte, los intelectuales provenientes del campo artístico y musical-teatral tienen poca relación con el sector editorial. Por lo que respecta a la industria periodisti$c a$, suelen ser grandes articulistas o di- 
rectores de periódicos importantes; tienen por lo general una presencia continuada y privilegiada en la gran prensa, a través de la crítica política, cultural o social; otros solo tienen una presencia indirecta a través de entrevistas, reportajes o críticas sobre su obra; también suelen ser grandes colaboradores de revistas literarias, de pensamiento o especializadas en diferentes disciplinas científicas y técnicas.

Por lo que respecta a la radio y la televisión, la vinculación de este tipo de profesionales intelectuales suele ceñirse a su presencia en programas de entretenimiento y entrevistas, pueden ser comentaristas políticos o culturales, o bien ceder la adaptación de sus obras literarias para la programación radiotelevisiva, al tiempo que -en el caso de los provenientes de la música y el teatro- suelen actuar directamente en el medio o bien a través de la autoría de bandas sonoras u obras teatrales. En el caso de la industria cinematográfica, su presencia es más bien escasa, salvo entre los grandes directores o autores de bandas sonoras. Finalmente, su presencia en la industria fonográfica solo se reduce a los autores e intérpretes del mundo musical.

En cuanto a su relación con las instituciones culturales públicas, esta se concreta en la obtención de becas, subvenciones, viajes y premios menores; en su participación en congresos, seminarios y simposios; en su acción en la universidad y en institutos de in- vestigación, en museos, exposiciones, festivales o teatros y en la obtención de algunos cargos públicos de prestigio, como la Biblioteca Nacional o el Instituto Cervantes, en el caso español.

\section{Trabajadores intelectuales (asalariados) de bajo rango}

El tipo de trabajadores intelectuales (asalariados) de bajo rango es en general más anónimo y numeroso; está repartido e integrado en el conjunto de las industrias culturales y comunicativas de todo tipo y características y su relación con estas es generalmente de subordinación. De todas maneras, los grandes medios de comunicación de masas - por su propia necesidad de creación de mitos populares- lanzan al estrellato a personajes que suelen partir desde muy abajo de la escala social y con una formación intelectual muy endeble, pero esto no es óbice para que, una vez en la cúspide de la popularidad, puedan beneficiarse ampliamente del sistema y, lo que es aún más importante, se conviertan en líderes de opinión con gran ascendencia sobre el público expuesto a los propios medios masivos.

Debido a la heterogeneidad de los trabajadores intelectuales proletarizados, resulta algo difícil su clasificación, pero su relación con la industria editorial, por ejemplo, suele centrarse, por una parte, en los trabajos de traducción, corrección de estilo, diseño, 
dibujos o carteles y, por otra, a la publicación de libros de tipo divulgativo y coyuntural o bien obras propias de la cultura de masas, como las novelas de kiosco. Su relación con la industria periodística suele ser también de dependencia laboral como asalariados: tal es el caso de los periodistas, publicitarios, diseñadores, grafistas, dibujantes de historietas, fotógrafos o divulgadores científicos.

Lo mismo ocurre con los servicios radiotelevisivos, que encuentran entre este tipo de trabajadores a los guionistas, redactores, publicitarios, diseñadores, realizadores, videoastas, divulgadores de todo tipo de ciencias o técnicas, actores, músicos o cantantes. Son también los guionistas y realizadores de la industria cinematográfica, sus diseñadores, sus actores y músicos. Por último, su relación con la industria fonográfica se ciñe a la composición o interpretación de canciones de moda, al diseño de portadas de discos, a la vez que pueden llegar a ser, sin mayores esfuerzos, grandes ídolos de la música de masas.

Su vinculación con el Estado suele ser también de dependencia laboral en la propia administración -ministerios de Cultura o de Educación y consejerías de Cultura y de Educación de las comunidades autónomas, entre otraso bien en el propio sector público de la industria cultural de masas, como RTVE, CCRTV, EITB o Agencia Efe en el caso español.

\section{Conclusiones}

Como ha recordado Nicholas Garnham, fueron Marx y Engels -en $L a$ ideología alemana- quienes afirmaron que en las sociedades capitalistas eran los detentadores del poder económico y político los que pagaban a ideólogos e intelectuales con su renta para poder controlar así también el poder ideológico, única manera de asegurar la reproducción de las relaciones sociales de producción (Althusser, 1975). Es decir, que Marx y Engels observaron con acierto que las actividades de gestión y dirección requieren una cohorte de trabajadores intelectuales que no son productivos en forma directa y cuyo precio de reproducción, en consecuencia, debe ser mantenido por la clase productora material. Puesto que en el capitalismo son los capitalistas los que extraen esa plusvalía, deben ser ellos quienes la distribuyan en actividades de dirección y gestión y, por tanto, ejerzan presiones directas sobre los ideólogos, que son sus "sirvientes a sueldo". 15

Por su parte, la clase trabajadora también desarrolló su propia cultura e ideología, para contraponerla a la cul-

15 GARNHAM, Nicholas. "Contribución a una economía política de la comunicación de masas", en MORAGAS, Miquel de (ed.). Sociología de la comunicación de masas. Barcelona: Gustavo Gili, 1985. 
tura e ideología dominantes, y pagó con su salario a sus propios "intelectuales orgánicos" -tales como sindicalistas, organizadores de cooperativas, periodistas o agitadores sociales-, pero el excedente disponible para este fin era escaso tanto real como comparativamente, por lo que este grupo ideológico privilegiado se inclinó claramente en favor del capital, y así permanece. ${ }^{16}$

Sin embargo, esta contratación directa de los ideólogos e intelectuales por parte de las clases sociales fundamentales -en particular, los poseedores de capital, a través de las industrias culturales y comunicativas- sufrió en España, por ejemplo, un decidido repliegue tras la Guerra Civil y el consiguiente protagonismo directo del Estado franquista, con el soporte incondicional de la jerarquía católica. La producción y reproducción cultural, tanto de élites como de masas, con su control, gestión y censura de todos los sectores de estas industrias -entre ellos y muy particularmente los medios de comunicación- quedó por tanto en las manos directas del Estado durante cuarenta años. Pero, tras la democratización del país y en el actual grado de desarrollo de estas industrias privadas -crecientemente en manos de grupos multimedios y de corporaciones transnacionales-, España no puede escapar más a la presión liberalizadora por parte del capital que invade todos los ámbitos culturales y comunicativos -tanto de soportes como de contenidos- y ya ha entrado definitivamente en un sistema cultural transnacional, al que corresponde, como es fácil suponer, un tipo de trabajador intelectual también transnacional.

\section{Bibliografía}

ALTHUSSER, Louis. "El Estado y los aparatos ideológicos", en MORODO, Raúl y Manuel PASTOR (eds.). Lecturas de ciencia politica: Enfoques teóricos. Madrid: Túcar Ediciones, 1975.

AYALA, Francisco. "El intelectual y los medios audiovisuales". Nueva Estafeta 8. Madrid, julio de 1979.

BERRIO, Jordi y Enric SAPERAS. Els intel.lectuals, avui. Barcelona: Institut d'Estudis Catalans, 1993.

BOZAL, Valeriano. Cultura y capitalismo. Madrid: Edicusa, 1982.

BRETON, Albert. "Introducción a una economía de la cultura: Un enfoque liberal". Industrias culturales: El futuro de la cultura en juego. México: FCE/Unesco, 1982. 
CUETO, Juan. "El quiosco de la ciencia barata". Triunfo 18. Madrid, abril de 1982.

D. A. Les professions de la cultura. 2 Vol. Barcelona: Institut Català de Noves Professions, 1993.

ECO, Umberto. Apocalipticos e integrados ante la cultura de masas. Barcelona: Lumen, 1968.

FAJARDO, José Manuel. "Los intelectuales y la resistible atracción del poder". Cambio 16 780. Madrid, 10 de noviembre de 1986.

GARNHAM, Nicholas. "Contribución a una economía política de la comunicación de masas", en MORAGAS, Miquel de. (ed.). Sociología de la comunicación de masas. Barcelona: Gustavo Gili, 1985.

GIRARD, Augustin. "Las industrias culturales: ¿Obstáculo o nueva oportunidad para el desarrollo cultural". Industrias culturales: el futuro de la cultura en juego. México: FCE/Unesco, 1982.

GRAMSCI, Antonio. Cultura y literatura. Madrid: Ediciones Península, 1967.

HORKHEIMER, Max y Theodor W. ADORNO. "La industria cultural". Industria cultural y sociedad de masas. Caracas: Monte Ávila Editores, 1974.
JONES, Daniel E. "Democràcia, comunicació i negoci: el creixement desmesurat de la concentració econòmica”. Trípodos 10. Barcelona: URL, 2001.

JULIÁ, Santos. "Intelectuales en periódicos: de la estrella polar al observatorio crítico". El País. Madrid, 11 de mayo del 2005.

KONRÁD, George e Ivan SZELENYI. Los intelectuales y el poder: "Intelligentsia" y poder de clase en los países socialistas europeos. Barcelona: Ediciones Península, 1981.

LACALLE, Daniel et al. Los trabajadores intelectuales y la estructura de clases. Madrid: Centro de Investigaciones Sociológicas, 1982.

MacDONALD, Dwight. "Masscult y midcult". Industria cultural y sociedad de masas. Caracas: Monte Ávila Editores, 1974.

MARTÍN SERRANO, Manuel. Los profesionales en la sociedad capitalista. Madrid: Pablo del Río Editor, 1977.

MATTELART, Armand y Jean-Marie PIEMME. "Las industrias culturales: génesis de una idea". Industrias culturales: El futuro de la cultura en juego. México: FCE/ Unesco, 1982.

MIGUEL, Amando de. Los intelectuales bonitos. Barcelona: Planeta, 1980. 
OVEJERO LUCAS, Félix. "El precio de los intelectuales". Revista de Libros 89. Madrid: Fundación Caja Madrid, mayo del 2004.

ROMANO, Vicente. Los intermediarios de la cultura: Los emisores en el proceso de comunicación social. Madrid: Pablo del Río Editor, 1977.

ROSITI, Franco. Historia y teoría de la cultura de masas. Barcelona: Gustavo Gili, 1980.
SCHLESINGER, Philipe et al. Los intelectuales en la sociedad de la información. Barcelona: Anthropos, 1987.

TOFFLER, Alvin. Los consumidores de cultura. Buenos Aires: Ediciones Siglo Veinte, 1967.

TOWSE, Ruth. Manual de economía de la cultura. Madrid: Fundación Autor, 2005.

WILLIAMS, Raymond. Cultura: Sociología de la comunicación y del arte. Barcelona: Paidós, 1982. 